\title{
Acceptor substrate determines donor specificity of an aromatic prenyltransferase: expanding the biocatalytic potential of NphB
}

\author{
Bryce P. Johnson ${ }^{1}$ • Erin M. Scull ${ }^{1}$. Dustin A. Dimas ${ }^{1} \cdot$ Tejaswi Bavineni $^{1} \cdot$ Chandrasekhar Bandari $^{1}$. \\ Andrea L. Batchev ${ }^{1}$ • Eric D. Gardner ${ }^{1}$ • Susan L. Nimmo ${ }^{1} \cdot$ Shanteri Singh $^{1}{ }^{1}$
}

Received: 13 January 2020 / Revised: 26 February 2020 / Accepted: 5 March 2020 / Published online: 18 March 2020

(C) The Author(s) 2020

\begin{abstract}
Aromatic prenyltransferases are known for their extensive promiscuity toward aromatic acceptor substrates and their ability to form various carbon-carbon and carbon-heteroatom bonds. Of particular interest among the prenyltransferases is NphB, whose ability to geranylate cannabinoid precursors has been utilized in several in vivo and in vitro systems. It has therefore been established that prenyltransferases can be utilized as biocatalysts for the generation of useful compounds. However, recent observations of non-native alkyl-donor promiscuity among prenyltransferases indicate the role of NphB in biocatalysis could be expanded beyond geranylation reactions. Therefore, the goal of this study was to elucidate the donor promiscuity of NphB using different acceptor substrates. Herein, we report distinct donor profiles between NphB-catalyzed reactions involving the known substrate 1,6-dihydroxynaphthalene and an FDA-approved drug molecule sulfabenzamide. Furthermore, we report the first instance of regiospecific, NphB-catalyzed $\mathrm{N}$-alkylation of sulfabenzamide using a library of non-native alkyl-donors, indicating the biocatalytic potential of $\mathrm{NphB}$ as a late-stage diversification tool.
\end{abstract}

\section{Key Points}

- NphB can utilize the antibacterial drug sulfabenzamide as an acceptor.

- The donor profile of NphB changes dramatically with the choice of acceptor.

- NphB performs a previously unknown regiospecific $N$-alkylation on sulfabenzamide.

- Prenyltransferases like NphB can be utilized as drug-alkylating biocatalysts.

Keywords Biocatalysis $\cdot$ Diversification $\cdot$ Alkyl-donor $\cdot N$-prenylation $\cdot$ Sulfabenzamide $\cdot$ Enzyme promiscuity

\section{Introduction}

Aromatic prenyltransferases (PTs) comprise a large class of enzymes catalyzing the transfer of a prenyl group from a prenyl-pyrophosphate donor onto an aromatic acceptor

Bryce P. Johnson and Erin M. Scull contributed equally to this work.

Electronic supplementary material The online version of this article (https://doi.org/10.1007/s00253-020-10529-8) contains supplementary material, which is available to authorized users.

Shanteri Singh

shanteri.singh@ou.edu

1 Department of Chemistry and Biochemistry, Stephenson Life Sciences Research Center, University of Oklahoma, 101 Stephenson Parkway, Norman, OK 73019, USA
(Awakawa and Abe 2019; Saleh et al. 2009). This reaction scheme, delivers a high level of chemical diversity among the products of PT reactions arising from a combination of factors (Kumano et al. 2008; Kuzuyama et al. 2005; Shindo et al. 2011; Tanner 2015; Tello et al. 2008). For example, the accepted prenyl groups can vary in size (5-carbon dimethyallyl, 10-carbon geranyl, 15-carbon farnesyl, 20carbon geranylgeranyl) between PTs, while the attachment can occur from either $\mathrm{C}^{\prime}$ or $\mathrm{C}^{\prime}$ of the prenyl donors onto various positions of the aromatic acceptors, resulting in normal or reverse prenylation, respectively (Giessen and Marahiel 2015; Winkelblech et al. 2015a). Furthermore, PTs have been shown to catalyze the formation of $\mathrm{C}-\mathrm{C}$ (ArayaCloutier et al. 2017; Bandari et al. 2019; Elshahawi et al. 2017; Fan et al. 2015b; Haagen et al. 2007; Winkelblech et al. 2015b), C-O (Bandari et al. 2017; Haagen et al. 2007; 
Kumano et al. 2008; Pockrandt et al. 2012; Rudolf et al. 2013; Shindo et al. 2011; Wunsch et al. 2015), C-N (Bonitz et al. 2013; Dalponte et al. 2018; Mahmoodi and Tanner 2013; Qian et al. 2012; Yin et al. 2007; Zou et al. 2011), and C-S bonds (Rudolf and Poulter 2013). Studies thus far reveal PTs to be highly flexible toward aromatic acceptors (Fan et al. 2015a; Kumano et al. 2008; Schuller et al. 2012; Shindo et al. 2011; Tanner 2015) as well as non-native alkyl donors (Bandari et al. 2019; Bandari et al. 2017; Liebhold and Li 2013; Liebhold et al. 2012; Liebhold et al. 2013; Yu et al. 2015). These promiscuous activities have been attributed to the spacious active site within the common PT fold, the ABBA motif, composed of 10 antiparallel $\beta$-strands forming a $\beta$-barrel and surrounded by $\alpha$-helices alternating in an $\alpha \beta \beta \alpha$ pattern (Kuzuyama et al. 2005; Saleh et al. 2009).

The motif was originally elucidated from the crystal structure of $\mathrm{NphB}$, a member of the $\mathrm{Mg}^{2+}$-dependent $\mathrm{CloQ} / \mathrm{NovQ}$ family of PTs (Kuzuyama et al. 2005). This particular PT is involved in the biosynthesis of naphterpin in Streptomyces sp. CL190 (Fig. 1a), where it has been recently proposed to transfer a geranyl group onto the $\mathrm{C} 4$ position of the putative substrate 1,3,6,8-tetrahydroxynaphthalene (Murray et al. 2018). Beyond this natural activity, though, NphB is known to exhibit a high degree of promiscuity toward phenolic acceptors, including flavonoids, isoflavonoids, plant polyketides, and various naphthols (Fig. 1b) (Kumano et al. 2008; Kuzuyama et al. 2005; Shindo et al. 2011; Xiao et al. 2009). Furthermore, most of these reactions resulted in several geranylated products differing in their regiochemistry. For the dihydroxynaphthalenes (DHNs), normal geranylation occurred at positions ortho to one of the hydroxy groups, though one instance of substitution para to a hydroxy group was observed for 1,6-DHN (Kumano et al. 2008; Kuzuyama et al. 2005). Alkylated naphthol derivatives showed similar patterns of normal ortho and para substitution, though normal $O$-geranylation was also observed on the single hydroxy group (Shindo et al. 2011). Most of the flavonoids were geranylated at C6 of the A ring (ortho to both hydroxy groups) and on the C7-hydroxy oxygen (Kumano et al. 2008; Kuzuyama et al. 2005), though a chrysin analog generated by Shindo et al. (2011) with 2,3-dihydroxylation of the $\mathrm{C}$ ring was geranylated para to the 2 -hydroxy moiety on this ring. Finally, the resorcinol derivatives underwent $C$-geranylation at $\mathrm{C} 2$ or $\mathrm{C} 4$, ortho to both or one hydroxy group respectively (Kumano et al. 2008; Qian et al. 2019; Valliere et al. 2019). As for non-GPP donors, NphB has been shown to utilize a terminal azido-substituted GPP derivative with 1,6-DHN, installing it ortho to the C6 hydroxy group, as well as farnesyl pyrophosphate (FPP) with 1,6-DHN and unreported regiospecificity (Kuzuyama et al. 2005; Xiao et al. 2009).

The established promiscuity of NphB, particularly with resorcinol derivatives, has focused attention on the enzyme in recent years for its biocatalytic potential. As a result, a handful of biocatalytic platforms have been developed using NphB for its natural geranylating activity. In 2017, the enzyme was recombinantly expressed in the yeast Komagataella phaffii with tetrahydrocannabinolic acid synthase from Cannabis sativa. The resulting lysate was shown to produce $\Delta^{9}$-tetrahydrocannabinolic acid from GPP and olivetolic acid (Zirpel et al. 2017), demonstrating the viability of $\mathrm{NphB}$ as a biocatalyst in the production of (a)

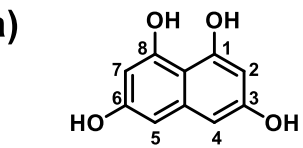

1,3,6,8-tetrahydroxynaphthalene

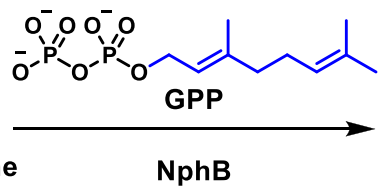

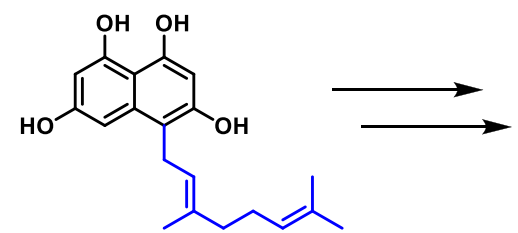

4-geranyl-1,3,6,8-tetrahydroxynaphthalene

(b)

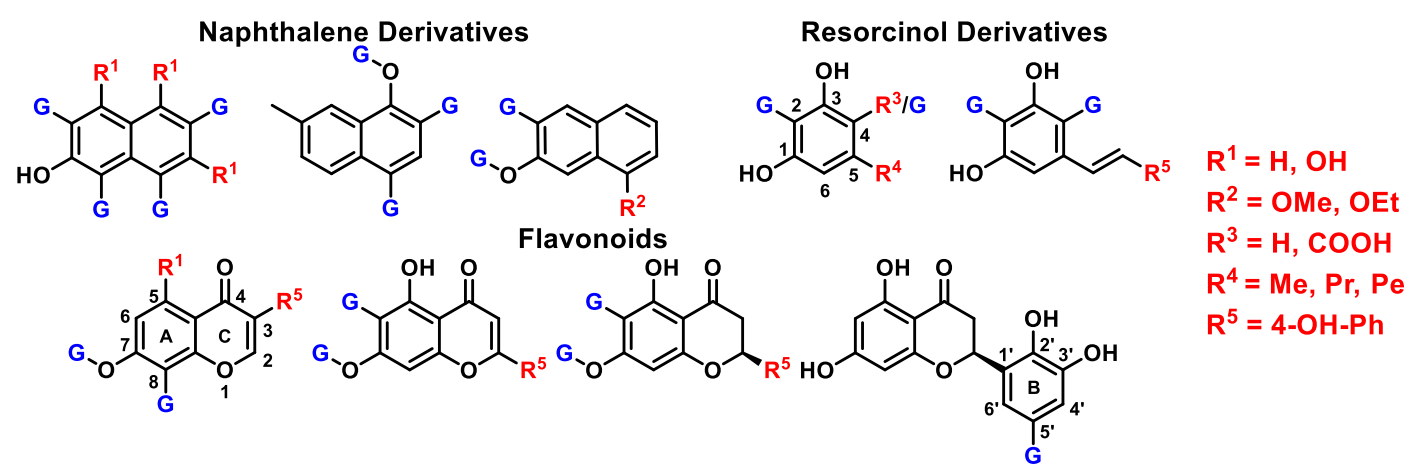

Fig. 1 Reactions of NphB. a Recently proposed role of NphB in naphterpin biosynthesis (Murray et al. 2018). b Known substrates of NphB. Each known site of geranylation is highlighted with a blue " $G$ " 
valuable cannabinoids. This initial utility was further expanded in 2019 when NphB was implemented in a multienzyme, "synthetic biochemistry" platform for the generation of various cannabinoids (Valliere et al. 2019). The optimized system, which included an $\mathrm{NphB}$ variant (G286SY288A) engineered to produce cannabigerolic acid (CBGA) almost exclusively from olivetolic acid, produced $1.25 \mathrm{~g} / \mathrm{L}$ of this cannabinoid over $24 \mathrm{~h}$. Furthermore, an in vivo system was published in the same year that produced geranylated phenolic acids, including CBGA, in Escherichia coli using an engineered $\mathrm{NphB}$ variant (G286S) (Qian et al. 2019). This study also established the NphB variant's ability to utilize farnesyl pyrophosphate (FPP) to a greater extent than the wild-type enzyme in the production of farnesylated phenolic acids. Overall, these studies have recontextualized $\mathrm{NphB}$ as a prominent biocatalyst whose prenylating activity is useful in the production of pharmacologically relevant compounds.

Nevertheless, the role of $\mathrm{NphB}$ presented in these works is limited mostly to its natural geranylating activity. The enzyme's utility as a biocatalyst could likely be expanded considering the wider promiscuities of PTs with respect to their alkyl-donors. Recent studies, including those with the tyrosine-O-PT SirD and the tryptophan C4-PT FgaPT2, have revealed the ability of PTs to transfer a wide array of non-native alkyl-groups onto both native and non-native aromatic acceptors (Bandari et al. 2019; Bandari et al. 2017; Liebhold and Li 2013; Liebhold et al. 2012; Liebhold et al. 2013; Winkelblech et al. 2015b; Yu et al. 2015). These types of late-stage functionalization reactions on aromatic rings are usually considered difficult to achieve with traditional synthetic chemistry (Hong 2014). Therefore, a biocatalyst capable of performing such reactions with predictable regiospecificity would be incredibly useful from a methodology perspective. Furthermore, facile access to these types of reactions opens a vast chemical space for pharmacologically relevant compounds, allowing one to conduct extensive structureactivity relationship (SAR) studies. Within this context, the precedence of $\mathrm{NphB}$ in biocatalytic systems provides a preemptive solution to the optimization of a new platform for late-stage modification. However, this platform can only be developed if $\mathrm{NphB}$ demonstrates activity with a range of non-native alkyl donors, of which only one (azido-GPP) has been confirmed (Xiao et al. 2009). Thus, the goal of this study was to elucidate NphB's ability to transfer a multitude of non-native alkyl groups from synthetic alkyl-pyrophosphates (alkyl-PPs) onto diverse and potentially useful aromatic acceptors. To this end, a panel of structurally disctint, aromatic drug molecules were screened for activity with $\mathrm{NphB}$ using two natural donors, DMAPP and GPP. From this initial screen, a single hit was identified: the antibacterial compound sulfabenzamide with DMAPP, a surprising result considering NphB's natural geranylating activity. To further investigate this donor promiscuity, a library of 66 unique alkyl-PP analogs was generated and tested using two acceptors, the known substrate 1,6-DHN and the newly discovered substrate sulfabenzamide. The subsequent activity assays demonstrated that $\mathrm{NphB}$ can transfer an array of non-native alkyl groups onto both acceptors, but the donor specificity of the enzyme depends heavily on the specific acceptor substrate. In addition, structural characterization of diverse sulfabenzamide derivatives revealed a previously unreported activity of NphB to perform regiospecific and chemoselective $N$-alkylation. Thus, the present study establishes alkyl-diversification as a legitimate biocatalytic pursuit for NphB while also illuminating the general considerations needed to utilize it.

\section{Materials and methods}

\section{General reagents and materials}

Unless otherwise stated, all chemicals and reagents were purchased from Sigma-Aldrich (St. Louis, MO, USA), Acros (New Jersey, USA), Alfa Aesar (Ward Hill, MA, USA), or TCI (Portland, OR, USA) and were reagent grade or better.

\section{Synthesis, purification, and characterization of alkyl-PP analogs}

Procedures for the synthesis of alkyl-pyrophosphate analogs 1, 2, 4-7, 9, 11-13, 17, 18, 20, 24-26, 37, 45-57 have been reported previously (Bandari et al. 2019; Bandari et al. 2017). All other analogs $(3,8,10,14-16,19,21-23,27-36,38-44$, 58-66) were synthesized using 1 equiv. of corresponding alcohol and an excess of bis(triethylammonium) phosphate (TEAP) solution. This solution $(25.0-100.0 \mathrm{mmol})$ was formed by mixing $36 \mathrm{~mL}$ reagent $\mathrm{A}(94 \mathrm{~mL}$ acetonitrile and $\left.25 \mathrm{~mL} \mathrm{H}_{3} \mathrm{PO}_{4}\right)$ and $60 \mathrm{~mL}$ reagent $\mathrm{B}(110 \mathrm{~mL}$ triethylamine and $100 \mathrm{~mL}$ acetonitrile). Each alcohol was first dissolved in $20 \mathrm{~mL}$ trichloroacetonitrile ( 25 equiv.) in a round-bottom flask and stirred at room temperature for a total of $25 \mathrm{~min}$, with $20 \mathrm{~mL}$ of TEAP solution being added to initiate the reaction and subsequently at both the 5- and 10-min time points. The products were purified by flash column chromatography in 7:2:1 isopropanol $/ \mathrm{NH}_{4} \mathrm{OH} / \mathrm{H}_{2} \mathrm{O}$, yielding white amorphous solids. The identity of each analog was confirmed by nuclear magnetic resonance (NMR) spectroscopy and either highresolution mass spectrometry (HRMS) or liquid chromatography mass spectrometry (LCMS) (Supplementary Material). NMR spectra were obtained on a Varian VNMRS $500 \mathrm{MHz}$ instruments at the NMR core facility of the Department of Chemistry and Biochemistry of the University of Oklahoma using $99.9 \% \mathrm{D}_{2} \mathrm{O}$ or DMSO- $\mathrm{D}_{6}$ with $0.05 \% \mathrm{v} / \mathrm{v}$ TMS. ${ }^{1} \mathrm{H}$, ${ }^{13} \mathrm{C}$, and ${ }^{31} \mathrm{P}$ chemical shifts were referenced to internal standards or solvent resonances. All NMR spectra were recorded at ambient temperature and processed using Mnova 
(Mestrelab Research, L.C., Santiago de Compostela, Spain). HRMS and LCMS data were obtained on an Agilent 6545QTOF W/1290 HPLC mass spectrometer at the mass spectrometry core facility of the Department of Chemistry and Biochemistry of the University of Oklahoma.

\section{Overexpression and purification of $\mathrm{NphB}$}

A synthetic gene of wild-type NphB (GenBank: BAE00106.1) was purchased from Genscript Biotech (Piscataway, NJ) with codons optimized (see Supplementary Material Fig. S1a) for expression in E. coli. This gene was inserted into the pET-28a to obtain a $\mathrm{N}$-terminal $\mathrm{His}_{6}$-tagged construct (full amino acid sequence in Supplementary Material Fig. S1b), and the resulting recombinant plasmid was transformed into E. coli Rosetta cells. After overnight growth, $3 \mathrm{~mL}$ of bacterial culture was transferred to 4-L flasks containing 1-1.2 L Luria-Bertani medium and $50 \mu \mathrm{g} \mathrm{mL}^{-1}$ kanamycin. Cultures were then grown at $37{ }^{\circ} \mathrm{C}$ and 220 RPM for approximately $4 \mathrm{~h}$. Once $\mathrm{OD}_{600}=0.6-0.8$, protein expression was induced by the addition of isopropyl $\beta$-D-1thiogalactopyranoside (IPTG, $0.5 \mathrm{mM}$ final), and the cultures were continually shaken at $220 \mathrm{RPM}$ and $20{ }^{\circ} \mathrm{C}$ for an additional 16-19 h. Cells were harvested by centrifugation, with the resulting pellets resuspended in a lysis buffer $(300 \mathrm{mM} \mathrm{NaCl}, 10 \mathrm{mM}$ imidazole, $50 \mathrm{mM}$ $\mathrm{NaH}_{2} \mathrm{PO}_{4} \mathrm{pH}$ 7.8). Cells were lysed by way of sonication on ice for $40 \mathrm{~min}$ in total in cycles of $20 \mathrm{~s}$ pulses followed by 30 s rest periods (Fisher Scientific Model FB505; Thermo Fisher Scientific, Waltham, MA). Cultures were disturbed gently after every $10 \mathrm{~min}$ of sonication to ensure complete lysis. To remove unwanted cellular debris and insoluble protein, the lysed cells were spun down at $16,000 \mathrm{RPM}$ for $1 \mathrm{~h}$ at $10^{\circ} \mathrm{C}$. The supernatant, containing the expressed recombinant $\mathrm{NphB}$ with an N-terminal His $_{6}$-tag, was purified using a $5-\mathrm{mL}$ Ni Sepharose resin affinity chromatography column from GE Healthcare (Piscataway, NJ). Protein was eluted at $1.5 \mathrm{~mL} / \mathrm{min}$ using a gradient of 2 to $10 \%$ solution $\mathrm{B}$ over $25 \mathrm{~mL}$, a gradient of 10 to $100 \%$ solution $\mathrm{B}$ over $50 \mathrm{~mL}$, and an isocratic flow of $100 \%$ solution $\mathrm{B}$ for $50 \mathrm{~mL}$ (solution $\mathrm{A}=$ $200 \mathrm{mM} \mathrm{NaCl}, 10 \mathrm{mM}$ imidazole, and $50 \mathrm{mM} \mathrm{NaH}_{2} \mathrm{PO}_{4}$ pH 7.8; solution $\mathrm{B}=200 \mathrm{mM} \mathrm{NaCl}, 500 \mathrm{mM}$ imidazole, and $50 \mathrm{mM} \mathrm{NaH} \mathrm{PO}_{4} \mathrm{pH} 7.8$ ). The purified protein was concentrated through centrifugal filtration and exchanged to a new buffer condition $(50 \mathrm{mM} \mathrm{KCl}, 25 \mathrm{mM}$ Tris- $\mathrm{HCl}$ pH 8) using a PD10 column from GE Healthcare. Purity was evaluated by SDS-PAGE (Supplementary Material Fig. S2), and the resulting protein bands indicated both a high grade of purity and the appropriate molecular weight $(\sim 36 \mathrm{kDa})$ for $\mathrm{NphB}$. Final protein concentration was determined using a NanoDrop ${ }^{\mathrm{TM}}$ One Microvolume
UV-vis Spectrophotometer (Thermo Fisher Scientific, Waltham, MA).

\section{Analytical NphB-catalyzed reactions}

Two sets of in vitro NphB analytical reactions were performed using the same conditions: (1) an initial screening of drug molecules to identify acceptor substrates of $\mathrm{NphB}$ and (2) a screen of the synthetic alkyl-PPs against the acceptors 1,6DHN and sulfabenzamide. The initial acceptor screen utilized DMAPP (2) and GPP (32) as potential donors and the following drug molecules as potential acceptors: amoxicillin, chloramphenicol, equilin, ethinylestradiol, mebendazole, pyrimethamine, sulfabenzamide, sulfadoxine, and tetracycline. Subsequent reactions were conducted in a final volume of $20 \mu \mathrm{L}$, consisting of $1.2 \mathrm{mM}$ alkyl-PP analogs, $1 \mathrm{mM}$ 1,6DHN (Alfa Aesar) or sulfabenzamide (Sigma-Aldrich), and $6 \mu \mathrm{M}$ purified $\mathrm{NphB}$ in a reaction buffer $(25 \mathrm{mM}$ Tris $\left.\mathrm{pH} 8.0,5 \mathrm{mM} \mathrm{MgCl}_{2}, 50 \mathrm{mM} \mathrm{KCl}\right)$. Reactions were incubated at $35^{\circ} \mathrm{C}$ for $16 \mathrm{~h}$ and quenched using $40 \mu \mathrm{L}$ cold methanol, which was followed by centrifugation ( $9000 \mathrm{~g}$ for $30 \mathrm{~min}$ ) to remove precipitated protein. Reaction analysis was completed using reverse-phase high-performance liquid chromatography (RP-HPLC) on an Agilent 1220 system equipped with a DAD detector, and it employed a Gemini-NX C-18 (5 $\mu \mathrm{m}, 4.6 \mathrm{~mm} \times$ $250 \mathrm{~mm}$ ) column (Phenomenex, Torrance, California, USA). 1,6-DHN analytical reactions were separated using the following method: gradient of $10 \% \mathrm{~B}$ to $100 \%$ B over $22 \mathrm{~min}$, isocratic flow of $100 \%$ B for 2 min, gradient of $100 \%$ B to $10 \% \mathrm{~B}$ over $0.1 \mathrm{~min}$, and isocratic flow of $10 \% \mathrm{~B}$ over $5.9 \mathrm{~min}$ $\left(\mathrm{A}=\mathrm{ddH}_{2} \mathrm{O}\right.$ with $0.1 \%$ TFA; $\mathrm{B}=$ acetonitrile $)$ at flow rate $=$

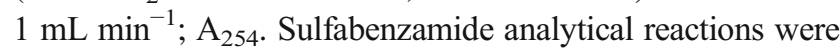
separated using the following method: gradient of $1 \% \mathrm{~B}$ to $10 \% \mathrm{~B}$ over $10 \mathrm{~min}, 10 \% \mathrm{~B}$ to $50 \% \mathrm{~B}$ over $5 \mathrm{~min}, 50 \% \mathrm{~B}$ to $100 \% \mathrm{~B}$ over $12 \mathrm{~min}, 100 \% \mathrm{~B}$ to $1 \% \mathrm{~B}$ over $1 \mathrm{~min}$, and isocratic flow of $1 \% \mathrm{~B}$ for $7 \mathrm{~min}\left(\mathrm{~A}=\mathrm{ddH}_{2} \mathrm{O}\right.$ with $0.1 \%$ TFA; $\mathrm{B}=$ acetonitrile) at flow rate $=1 \mathrm{~mL} \mathrm{m^{-1 }} ; \mathrm{A}_{254}$. The reactions were monitored by the retention time differences between the starting material and product(s).

\section{Large-scale NphB-catalyzed sulfabenzamide reactions}

$\mathrm{NphB}$ large-scale reactions were conducted in a volume of $10 \mathrm{~mL}$ consisting of $4.16 \mathrm{mM}$ alkyl-PP analog, $6 \mathrm{mM}$ sulfabenzamide, and $10 \mu \mathrm{M}$ purified $\mathrm{NphB}$ in a reaction buffer (25 mM Tris pH 8.0, $\left.5 \mathrm{mM} \mathrm{MgCl}_{2}, 50 \mathrm{mM} \mathrm{KCl}\right)$. Putative products were subsequently isolated by semi-preparative RPHPLC on an Agilent 1220 system equipped with a DAD detector. The method used a Gemini-NX, C-18 (5 $\mu \mathrm{m}, 10 \times$ $250 \mathrm{~mm}$ ) column (Phenomenex, Torrance, California, USA) to purify the sulfabenzamide analogs (gradient of $1 \% \mathrm{~B}$ to $10 \% \mathrm{~B}$ over $10 \mathrm{~min}, 10 \% \mathrm{~B}$ to $50 \% \mathrm{~B}$ over $5 \mathrm{~min}, 50 \%$ B to $100 \% \mathrm{~B}$ over $12 \mathrm{~min}, 100 \% \mathrm{~B}$ to $1 \% \mathrm{~B}$ over $1 \mathrm{~min}$, and 
isocratic flow of $1 \% \mathrm{~B}$ for $7 \min \left(\mathrm{A}=\mathrm{ddH}_{2} \mathrm{O}\right.$ with $0.1 \%$ formic acid; $\mathrm{B}=$ acetonitrile) flow rate $=2 \mathrm{~mL} \mathrm{~min}^{-1} ; \mathrm{A}_{254}$ ). The identity of each derivative was confirmed by NMR spectroscopy and HRMS using positive (+) and/or negative (-) mode(s) as previously described for the alkyl-PP analogs.

\section{In silico docking studies}

Sulfabenzamide was manually docked into the crystal structure of wild-type $\mathrm{NphB}$ originally containing 1,6-DHN and GSPP (PDB ID: 1ZB6, Kuzuyama et al. 2005) using PyMol (Schrödinger, New York City, NY).

\section{Results}

\section{Identification of sulfabenzamide as an acceptor substrate for NphB}

Initial analytical screens using two natural prenyl donors, 2 and 32, were performed to test the acceptor promiscuity of $\mathrm{NphB}$ toward various drug scaffolds (Fig. 2). Based on the known acceptor profile of $\mathrm{NphB}$ (Fig. 1b), potential acceptors were chosen based on the inclusion of phenol or a phenol-like moiety with unsubstituted positions ortho to the hydroxy or analogous group. Of all eighteen reactions tested on an analytical scale, only one showed turnover via RP-HPLC: sulfabenzamide with $\mathbf{2}$, which was surprising given the enzyme's native geranylating activity (Kumano et al. 2008; Kuzuyama et al. 2005; Shindo et al. 2011). Thus, the new findings implied a potential link between acceptor and donor specificity which could further expand the utility of $\mathrm{NphB}$ in biocatalytic systems if fully elucidated. To more firmly establish this link, a library of diverse alkyl-PPs was synthesized and screened against the newly identified acceptor as well as the known acceptor 1,6-DHN.

\section{Synthesis of alkyl-PP library}

The design of alkyl-PP analogs (Fig. 3) was consistent with the need of PTs to accept alkyl-donors containing a double bond at the $\beta$-position (Bandari et al. 2017). With this limitation in mind, the final library of 66 native and non-native alkyl-PP analogs, roughly demarcated between allylic (1-44) and aromatic (45-66) groups, was synthesized to explore as large of a chemical space as was feasible. The allylic analogs were designed either to match the natural prenyl donors dimethylallyl pyrophosphate (DMAPP, 2), geranyl pyrophosphate (GPP, 32), and farnesyl pyrophosphate (FPP, 42) (Winkelblech et al. $2015 \mathrm{a}$ ) or to resemble them with variations in alkylchain length, electronic character, and the presence or positioning of branching methyl groups. The resulting library included aliphatic analogs published previously (1, 4-7, 9, 11-13, 17, 18, 20, 24-26, 37) (Bandari et al. 2019; Bandari et al. 2017), novel GPP derivatives with various terminal groups $(\mathbf{3 5}, \mathbf{3 6}, \mathbf{4 0}, \mathbf{4 1}, \mathbf{4 3}, \mathbf{4 4})$, and new alkyl-PP analogs with chain lengths between DMAPP and GPP (21-23, 31). The aromatic donors were similarly designed to test variations in the number and position of benzene substitutions, the effect of electron-donating and electronwithdrawing groups on the benzene ring, and the presence of various heteroaromatic systems. Syntheses and utility of most of the benzylic alkyl-PPs were published previously to demonstrate their acceptability with the tyrosine$O$-PT SirD and the tryptophan $C 4-\mathrm{PT}$ FgaPT2 (45-57) (Bandari et al. 2019), but three novel benzylic analogs were synthesized to either understand the effects of conformational constraint (58) or to introduce synthetic handles $(\mathbf{5 9}, \mathbf{6 0})$. Furthermore, the abundance of heterocycles across the spectrum of known drugs (Taylor et al. 2016) prompted the synthesis of novel alkyl-PPs with diverse heteroaromatic characters (61-66). Finally, to explore the potential applications of alkylated products, a small pool of alkyl-PPs was synthesized to contain functionalities
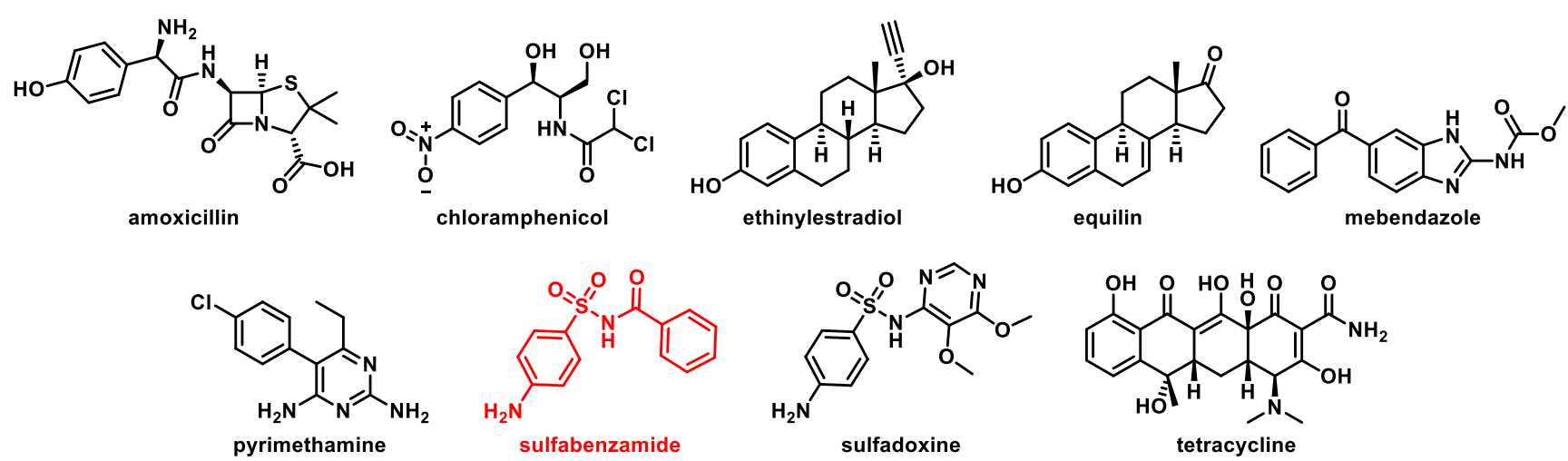

Fig. 2 Drug molecules screened as potential acceptors in NphB-catalyzed reactions. The identified hit is highlighted in red 


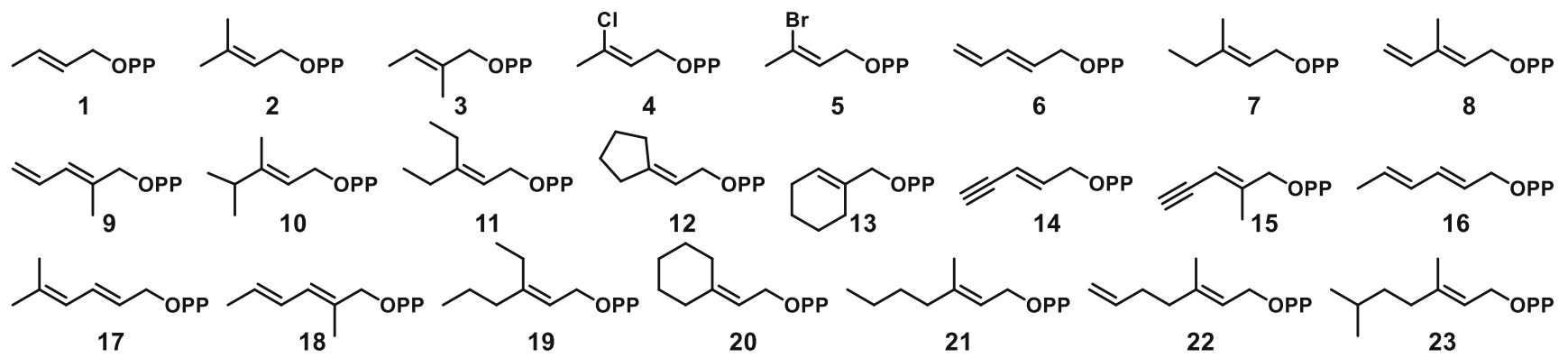

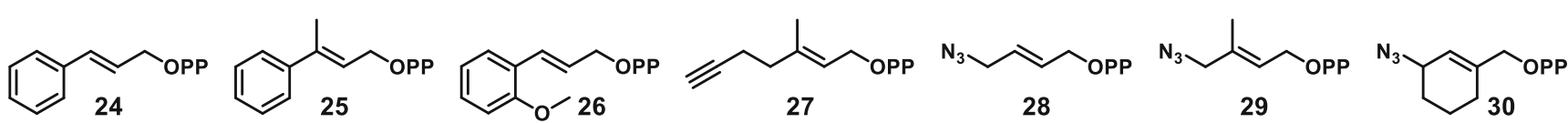<smiles>C#CCOC/C(=C/COP)COC/C=C(\C)CC/C=C(\C)CCC=C(C)C</smiles><smiles>C=CCC/C(C)=C/C/C=C(\C)C/C=C/COc1ccccc1</smiles>

32<smiles>C=CC/C=C(\C)C/C=C/C/C=C(\C)CCOc1ccccc1</smiles><smiles>CC/C(C)=C/CC/C(C)=C/CO</smiles><smiles>C#CCOC/C(C)=C/CC/C(C)=C/COC/C=C(\C)CC/C=C(\C)CC/C=C(\C)CC/C=C(\C)CCOc1ccccc1</smiles><smiles>CC(=CCOc1ccccc1)CC=C(C)COCc1ccccc1</smiles>
41 42<smiles>Fc1cc(P)cc(COc2ccccc2)c1</smiles><smiles>POCc1ccc(Cl)cc1</smiles><smiles>Brc1ccc(COc2ccccc2)cc1</smiles>

44<smiles>c1ccc(COc2ccccc2)cc1</smiles>

45<smiles>COc1ccc(COP)cc1</smiles>

52<smiles>C#CCOc1ccc(COc2ccccc2)cc1</smiles>

59
46<smiles>Fc1ccc(COc2ccccc2)cc1</smiles>

47

49

50<smiles>O=[N+]([O-])Cc1ccc([OH+])cc1</smiles>

51<smiles>COc1ccc(COc2ccccc2)cc1</smiles>

55<smiles>COc1ccc(COc2ccccc2)cc1OC</smiles>

54<smiles>COc1cc(COc2ccccc2)cc(OC)c1OC</smiles><smiles>POCc1ccc2c(c1)OCO2</smiles><smiles>c1ccc(OCc2cccs2)cc1</smiles>

62<smiles>[Pb]OCc1cscn1</smiles>

63<smiles>c1ccc(OCc2ccccn2)cc1</smiles>

64<smiles>CCOc1cc2ccccc2o1</smiles>

65<smiles>c1ccc(OCc2csc3ccccc23)nc1</smiles>

66

Fig. 3 Library of alkyl-PP analogs used in this work

amenable to either selective downstream chemistry or direct utility in research settings: alkynes $(\mathbf{1 4}, \mathbf{1 5}, \mathbf{2 7}, \mathbf{3 3}$, 43, 59) and azides $(28-30,34,60)$ for $\mathrm{Cu}$-mediated click chemistry (Meghani et al. 2017), dienes $(\mathbf{6}, \mathbf{8}, \mathbf{9}, \mathbf{1 6}-\mathbf{1 8}$, 37) and terminal alkenes $(\mathbf{2 2}, \mathbf{4 0})$ for Diels-Alder chemistry (Bouchez et al. 2016; Gregoritza and Brandl 2015), and fluorescent probes $(\mathbf{3 8}, \mathbf{3 9})$ for bioimaging $(\mathrm{Lu}$ et al. 2019). With these factors in mind, the final alkyl-PP library contained 66 compounds that covered a vast chemical space and was capable of thoroughly probing the donor specificity of NphB.

\section{Donor profiles of 1,6-DHN and sulfabenzamide with NphB}

1,6-DHN was chosen as one of the acceptor substrates for this study due to its status as the putative substrate of $\mathrm{NphB}$ and its assumed similarity to the true natural acceptor (Kuzuyama et al. 2005). Therefore, it was screened against the 66 alkyl-
PPs in analytical scale reactions using $\mathrm{NphB}$ as the catalyst. The resulting profile (Fig. 4, Supplementary Material Table S1 and Fig. S3) indicates the enzyme transferred 14 of the 66 analogs, of which 13 were allylic $(\mathbf{7}, \mathbf{1 0}, \mathbf{1 8}, \mathbf{2 1}, \mathbf{2 2}, \mathbf{2 7}, \mathbf{3 1}$, $32,35,37,42-44)$ and one was benzylic (59). In terms of quantified conversion, a single analog (32, GPP) showed $>$ $50 \%$, two $(\mathbf{3 5}, \mathbf{4 3})$ showed $>30 \%$, two $(\mathbf{2 1}, \mathbf{3 1})$ showed 20 $25 \%$, three $(\mathbf{1 8}, \mathbf{2 2}, \mathbf{4 2})$ showed $10-20 \%$, and the remaining six $(7,10,27,37,44,59)$ showed $<10 \%$. Furthermore, the chromatograms of five reactions $(18,32,35,42,43$, Supplementary Material Fig. S3) indicated the formation of multiple products. Based on these observations and the correlating structures (Fig. 4a), NphB generally tended to transfer groups onto 1,6-DHN with longer ( $>6$ unbranched carbons) aliphatic chains usually lacking bulky aromatic rings or hydrophilic moieties within 5 unbranched carbons of the pyrophosphate. Within this generalized aliphatic structure, the natural geranyl donor 32 showed the highest turnover at $62 \pm 6 \%$, while even relatively minor modifications to the geranyl 


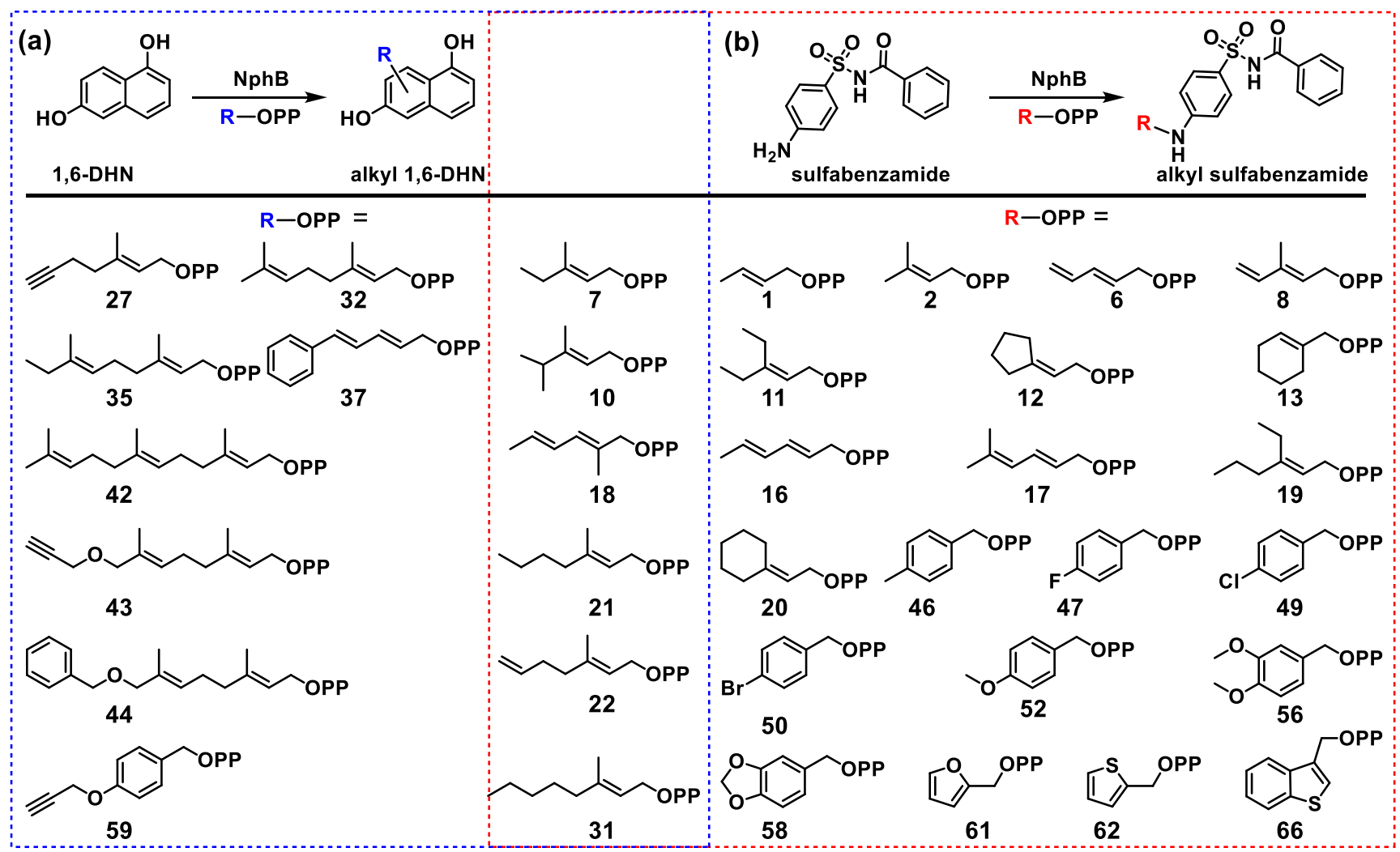

(c)

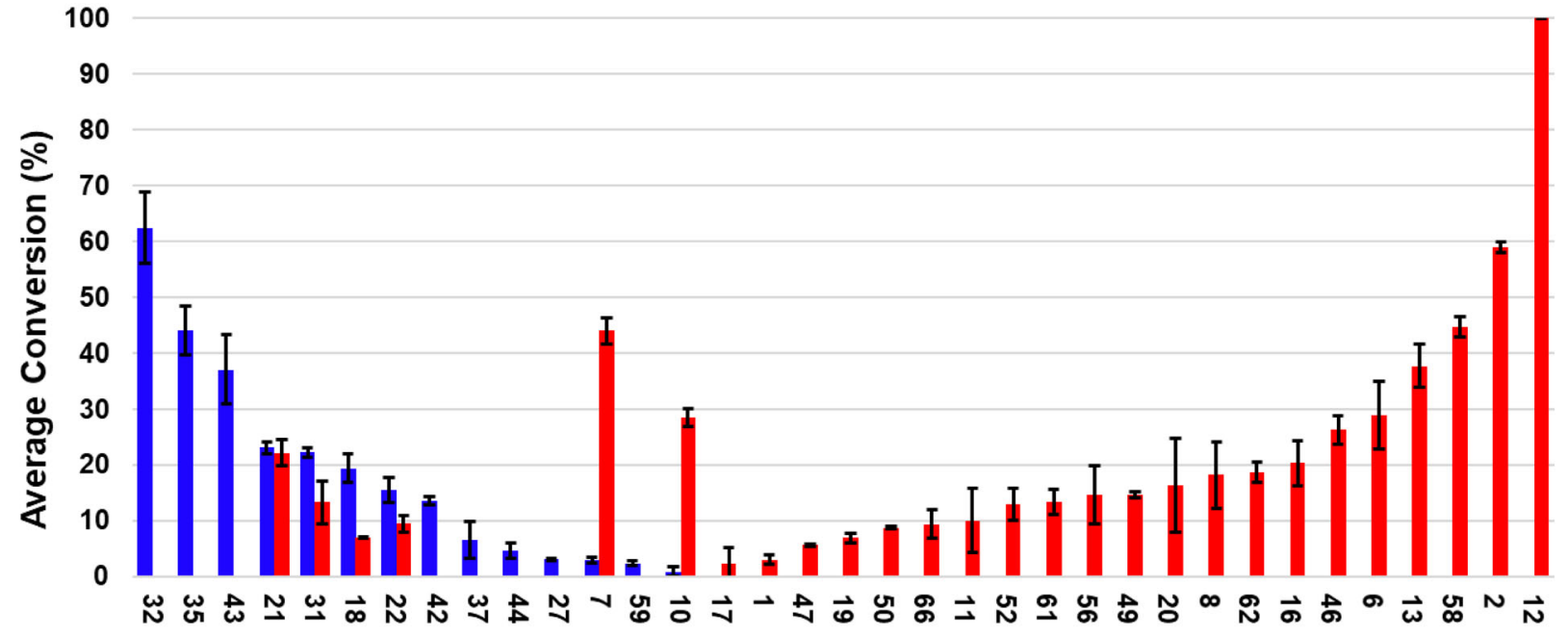

Alkyl-PP Analog

Fig. 4 Donor profiles of wild-type NphB-catalyzed reactions with acceptors 1,6-DHN and sulfabenzamide. a The general reaction scheme of donor screening with 1,6-DHN and the utilized alkyl-PP donors (boxed in blue). b The general reaction scheme of donor screening with sulfabenzamide and the utilized alkyl-PP donors (boxed in red). Analogs contained in both boxes were utilized with both acceptors. $\mathbf{c}$
Conversion rates of successful analytical scale reactions between aromatic acceptors and alkyl-PP donors, using the same color scheme as in a and b. Each reaction was carried out in a $20-\mu \mathrm{L}$ volume and contained $1.2 \mathrm{mM}$ alkyl-PP analog, $1 \mathrm{mM}$ 1,6-DHN or sulfabenzamide, and $6 \mu \mathrm{M}$ purified $\mathrm{NphB}$ in a reaction buffer consisting of $25 \mathrm{mM}$ Tris $\mathrm{pH} 8.0,5 \mathrm{mM} \mathrm{MgCl}_{2}, 50 \mathrm{mM} \mathrm{KCl}$ incubated at $35^{\circ} \mathrm{C}$ for $16 \mathrm{~h}$ scaffold (terminal methylation with $\mathbf{3 5}$, terminal didemethylation with 22) resulted in much reduced conversion (difference $>10 \%$ ) compared with 32. As for functionalized moieties, NphB utilized three alkynes $(\mathbf{2 7}, \mathbf{4 3}, \mathbf{5 9})$, two dienes $(\mathbf{1 8}, \mathbf{3 7})$, and the shorter terminal alkene (22). Though the turnovers for most of these reactions were low $(<10 \%)$, the success of these reactions, particularly with $\mathbf{4 3}$, hints at the possibility of using $\mathrm{NphB}$ to introduce chemical handles on 
molecules for downstream chemistry. In terms of its general utility, however, NphB appears to prefer GPP and its derivatives for alkylation of 1,6-DHN.

Sulfabenzamide was screened against the alkyl-PP library under the same conditions as 1,6-DHN (Fig. 4b, Supplementary Material Table S2). The resulting donor profile contained twenty-seven alkyl-PPs in total, split among seventeen allylic moieties $(\mathbf{1}, \mathbf{2}, \mathbf{6}-\mathbf{8}, \mathbf{1 0}-\mathbf{1 3}, \mathbf{1 6}-\mathbf{2 2}, \mathbf{3 1})$, seven benzylic groups $(\mathbf{4 6}, \mathbf{4 7}, \mathbf{4 9}, \mathbf{5 0}, \mathbf{5 2}, \mathbf{5 6}, \mathbf{5 8})$, and three heterocycles $(\mathbf{6 1}, \mathbf{6 2}, \mathbf{6 6})$. Two of these alkyl-PPs showed conversion $>50 \%(\mathbf{2}, \mathbf{1 2})$, six showed $25-50 \%(\mathbf{6}, 7, \mathbf{1 0}, \mathbf{1 3}, \mathbf{4 6}, \mathbf{5 8})$, eleven showed 10-25\% (8, 11, 16, 20, 21, 31, 49, 52, 56, 61, 62), and the remaining eight showed $<10 \%(\mathbf{1}, \mathbf{1 7}-\mathbf{1 9}, \mathbf{2 2}, \mathbf{4 7}$, 50, 66). All reactions, however, seemed to have generated a single product based on the chromatograms (Supplementary Material Fig. S4). Analysis of the accepted analog structures (Fig. 4b) revealed $\mathrm{NphB}$ tended to transfer aliphatic groups onto sulfabenzamide with short carbon chain lengths ( $\leq 6$ unbranched carbons) while also accommodating several aryl $(46,47,49,50,52,56,58,61,62,66)$ and non-aromatic cyclic $(12,13,20)$ groups close to $\mathrm{Cl}^{\prime}$ of the donor. In fact, despite 2 being the natural prenyl donor DMAPP, the cyclopentyl ana$\log 12$ showed the greatest conversion at a consistent $100 \%$ (compared with $58.9 \pm 0.9 \%$ for 2 ). The compound with the third highest conversion $(45 \pm 2 \%)$ was also cyclic, the benzodioxole-containing benzylic analog $\mathbf{5 8}$. As for the functionalized alkyl-PPs, NphB transferred six in total, including five dienes $(\mathbf{6}, \mathbf{8}, \mathbf{1 6}-\mathbf{1 8})$ and a single terminal alkene (22). Three of these moieties (dienes $\mathbf{6}, \mathbf{8}, \mathbf{1 6}$ ) even showed conversion $>10 \%$, with $\mathbf{6}$ approaching $\sim 30 \%$. This is in stark contrast to 1,6-DHN, where all the functionalized alkyl-PPs turned over $>10 \%$ using standard reaction conditions. The simple switch in acceptor increasing the activity of $\mathrm{NphB}$ with these types of groups provides further evidence of its possible utility in introducing reactive handles onto aromatic scaffolds. Overall, though, the choice of sulfabenzamide as the acceptor substrate appears to limit the donor specificity to DMAPP, DMAPP derivatives, and compounds with cyclic moieties attached within 2 carbons lengths of $\mathrm{Cl}^{\prime}$.

Taken together, the donor profile of sulfabenzamide was distinct from that of 1,6-DHN (Fig. 4). Although six donors were utilized with both acceptors $(7,10,18,21,22,31)$, the switch from 1,6-DHN to sulfabenzamide introduced new activity with twenty-one donors not previously observed $(\mathbf{1}, \mathbf{2}, \mathbf{6}$, $8,11-13,16,17,19,20,46,47,49,50,52,56,58,61,62,66)$. Most of these were alkyl-PPs with short allylic chains $(\sim 6$ unbranched carbons), though several benzylic groups and three heterocycles were also utilized. Thus, the major difference between the donors exclusive to one acceptor seems to be their generalized sizes (both length and nature of substituent). This trend even holds for the overlapping alkyl-PPs, as the smaller analogs ( $\leq 5$ unbranched carbons: $7, \mathbf{1 0})$ gave conversions at least $15 \%$ higher with sulfabenzamide than with 1,6-
DHN. Meanwhile, overlapping groups with chains of intermediate length (6-8 unbranched carbons: 18, 21, 22, 31) displayed either greater conversion ( $\sim 7 \%$ difference) or comparable conversion with 1,6-DHN. Collectively, the donor profiles of 1,6-DHN and sulfabenzamide establish a dependency of donor substrate specificity on the acceptor substrate in NphB-catalyzed reactions.

\section{Determination of regiospecificity in sulfabenzamide reactions}

Consistent with the known multi-site prenylation of 1,6-DHN by NphB (Kumano et al. 2008; Kuzuyama et al. 2005), the HPLC chromatograms of several reactions $(\mathbf{1 8}, \mathbf{3 2}, \mathbf{3 5}, \mathbf{4 2}, \mathbf{4 3}$, Supplementary Material Fig. S3) of 1,6-DHN by NphB indicated the presence of multiple products. In contrast, NphBcatalyzed alkylation reactions with sulfabenzamide resulted in a single product. Therefore, to understand the regioselectivity of the newly discovered activity with sulfabenzamide, a representative set of diverse sulfabenzamide reactions were scaled up, purified by semi-preparative RP-HPLC, and characterized by NMR spectroscopy. Most of the analyzed products came from reactions displaying $>25 \%$ average conversion in the initial analytical screen and possessed an alkyl group with unique electronic or structural features, i.e., carbon chain length, conjugated systems, cyclization, and aromaticity. These include derivatives obtained from reactions with DMAPP (2); ethyl and isopropyl DMAPP derivatives (7, 10); diene analogs with unbranched carbon chain lengths of 5 and $6(\mathbf{6}, \mathbf{1 6})$; two non-aromatic, cyclized pyrophosphates $(12,13)$; and two benzylic analogs $(46,58)$. Additionally, the successful reactions with heterocyclic donors $(\mathbf{6 1}, \mathbf{6 2})$ were included due to the prevalence of heterocycles in medicinal chemistry (Taylor et al. 2016). The resulting purified sulfabenzamide products were subjected to ${ }^{1} \mathrm{H}$ and $\mathrm{COSY}$ experiments. Additionally, HMBC and HSQC spectra were recorded for representative sufabenzamide derivatives of $\mathbf{1 0}$, 58,61 , and 62 for unambiguous determination of the position of alkylation.

The complete NMR analysis (chemical shift values, splitting pattern, COSY and/or HMBC correlations) of all scaledup sulfabenzamide products established that NphB-catalyzed regiospecific and chemoselective $\mathrm{N}$-alkylation of the 4aminobenzenesulfonyl ring (Fig. 5, Supplementary Material Table S5). The ${ }^{1} \mathrm{H}$ NMR of the derivatives, when compared with the parent sulfabenzamide, revealed all aromatic protons in the 6.0-8.0 ppm range which were accounted for on both rings of the parent compound, strongly suggesting an $N$-substitution. Signals corresponding to the two aromatic rings could be differentiated by their splitting pattern, with the benzamide ring displaying three distinct mutliplet peaks integrating to a 2:2:1 ratio and the 4-aminobenzenesulfonyl ring having two doublet peaks integrating to two protons each. 


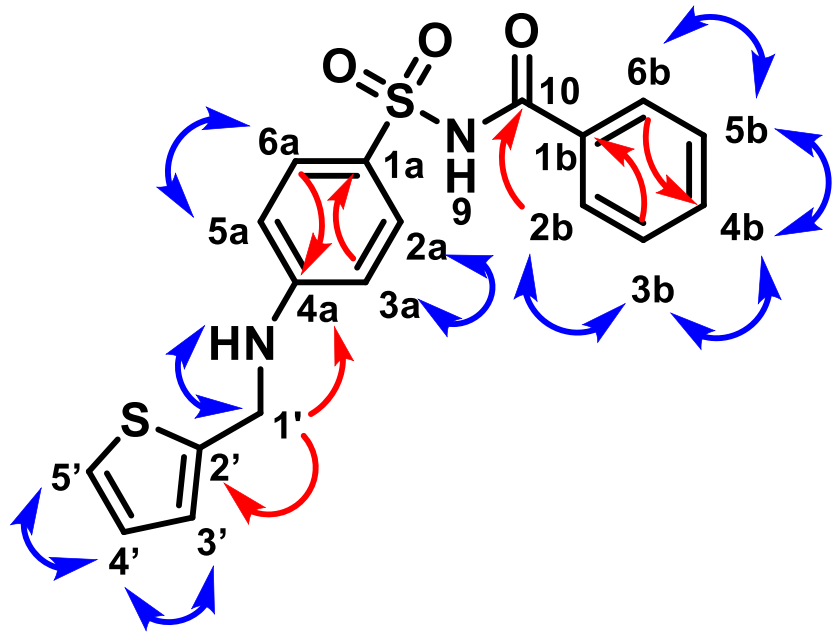

Fig. 5 A representative example (77) of NMR correlations for scaled-up sulfabenzamide derivatives. Observed ${ }^{1} \mathrm{H}_{-}{ }^{1} \mathrm{H}$ COSY correlations are shown as blue double-headed arrows. Relevant ${ }^{1} \mathrm{H}-{ }^{13} \mathrm{C}$ HMBC correlations are shown as red single-headed arrows

Assignments of the aromatic proton signals were further supported by the COSY spectra showing correlation peaks between the $\mathrm{H} 2 \mathrm{a} / 6 \mathrm{a}-\mathrm{H} 3 \mathrm{a} / 5 \mathrm{a}$ on the 4 -aminobenzenesulfonyl ring as well as correlation peaks between $\mathrm{H} 2 \mathrm{~b} / 6 \mathrm{~b}-\mathrm{H} 3 \mathrm{~b} / 5 \mathrm{~b}$ and $\mathrm{H} 4 \mathrm{~b}-\mathrm{H} 3 \mathrm{~b} / 5 \mathrm{~b}$ on the benzamide ring (see Supplementary Material). In some cases, the COSY spectra also showed a correlation between the proton on the amino $\mathrm{NH}$ and the $\mathrm{H}^{\prime}$ of the substituent alkyl or benzyl group. In addition, the ${ }^{1} \mathrm{H}-{ }^{13} \mathrm{C}$ HMBC and ${ }^{1} \mathrm{H}_{-}{ }^{13} \mathrm{C}$ HSQC spectra displayed characteristic resonances and connectivity between $\mathrm{H} 1$ ' of the donor group and the $\mathrm{C} 4 \mathrm{a}$ of the 4-aminobenzenesulfonyl ring, unequivocally confirming the $N$-alkylation. Each scale up reaction was additionally confirmed by HRMS data, supporting the presence of a single mono-alkylated product per reaction (Supplementary Material Table S4). To our knowledge, this is the first reported instance of NphB-catalyzed $N$-alkylation, which further expands the applicability of $\mathrm{NphB}$ in biocatalytic systems involving alkylation of natural products.

\section{Discussion}

The donor profiles of 1,6-DHN and sulfabenzamide in reactions catalyzed by $\mathrm{NphB}$ showed highly distinct trends, with 1,6-DHN favoring longer aliphatic moieties ( $~ 8-9$ unbranched atoms) and sulfabenzamide showing a preference for shorter ones ( 5-6 unbranched atoms). Furthermore, NphB catalyzed far more reactions with aromatic alkyl-PPs, both benzylic and heterocyclic, when sulfabenzamide was the acceptor (twelve vs. two with 1,6-DHN), while only reactions with 1,6-DHN could form multiple products. To explain the observed trends, sulfabenzamide was docked in the active site of the $\mathrm{NphB}$ crystal structure bound to geranylthiolopyrophosphate (GSPP) and 1,6-DHN (PDB ID: 1ZB6; Kuzuyama et al.
2005; Fig. 6a). In the crystal structure, the geranyl tail of GSPP is highly stabilized through $\pi-\pi$ stacking interactions with 1,6-DHN and Tyr121, along with additional hydrophobic interactions with Val49, Phe123, Met162, and Tyr288 (Fig. 6a). In the docked model, sulfabenzamide replaced 1,6-DHN and was placed in a similar orientation, such that the amine group was within hydrogen bonding distance to $\mathrm{C}^{\prime}$ of the donor to facilitate $N$-alkylation (Fig. 6b) as observed (67-77). The NphB structure, along with the docked model, indicates a reduction in available space that occurred in the active site when switching from 1,6-DHN to sulfabenzamide (Fig. 6), which can be rationalized by each molecule's structure. In terms of the relative size, sulfabenzamide would be considered larger than 1,6-DHN based solely on the number of nonhydrogen atoms in each (19 and 12, respectively). Additionally, the fused bicyclic aromatic system of 1,6-DHN causes it to be planar and compact, while the flexible sulfonamide linker of sulfabenzamide introduces both threedimensionality and a greater two-dimensional distance between the ends of the rings. This linker would thus force the unsubstituted ring to partially occlude the donor binding site (Fig. 6b). Coupled with the inherent rigidity of the geranyl group, this occlusion would likely cause GPP to be excluded from the active site and no product to be formed, matching the experimental data obtained in this study. The occlusion would also explain the generally shorter alkyl groups transferred onto sulfabenzamide, as they would fit more easily into the reduced active site space. NphB did, however, show measurable conversion for sulfabenzamide with 31, a GPP homolog missing a terminal methyl group and the $\mathrm{C} 6^{\prime}-\mathrm{C} 7^{\prime}$ double bond. Although the two alkyl-PPs are approximately of the same length from end to end, the removal of these two features most likely increases the flexibility of the chain in $\mathbf{3 1}$ such that the last four $\mathrm{C}-\mathrm{C} \sigma$ bonds can freely rotate away from the occluding ring of sulfabenzamide. The required rotations would, however, greatly reduce the number of conformations viable for reaction, thus decreasing the conversion of $\mathbf{3 1}$ compared with an alkyl group like 2 small enough to fit in the active site without additional rotation. This could explain the relatively low conversion of $\mathbf{3 1}$ $(13.3 \pm 3 \%)$ compared with $2(58.9 \pm 0.9 \%)$.

Size alone, however, is not enough to explain the finer trends in the diverse donor profile of sulfabenzamide. The mechanism of NphB-catalyzed reactions, in which the carbocation is attacked by the nucleophilic acceptor (Luk and Tanner 2009), exists in a delicate equilibrium of stability, as it must be (i) stabilized enough to exist before the nucleophilic attack (Yang et al. 2012) and (ii) desolvated completely to prevent premature quenching (Lesburg et al. 1998). Both the active site residues and the donor structure contribute to this balance in complex ways. For example, PTs often contain aromatic residues like Tyr, Trp, and Phe in the donor binding site to introduce $\pi-\pi$ stacking interactions that further stabilize the 


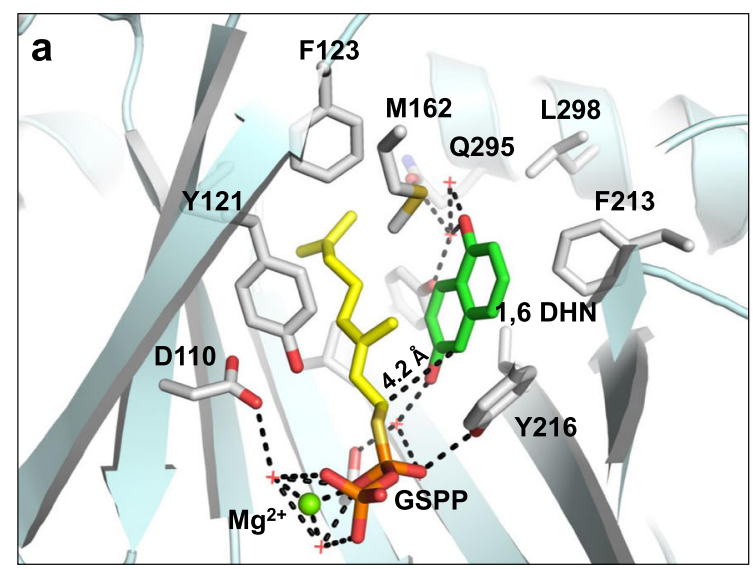

Fig. 6 a Active site structure of NphB bound to 1,6-DHN and GSPP (PDB ID: 1ZB6, Kuzuyama et al. 2005). b A docked model of the $\mathrm{NphB}$ active site containing sulfabenzamide with its amine group

allylic carbocation (Metzger et al. 2010). Therefore, to interpret the finer details of the donor profiles considering the same active site and acceptor, one must closely inspect both the steric and electronic differences between donors that may contribute to carbocation stability and reactivity. Within this context, the highest conversion in the sulfabenzamide analytical screens was observed with $\mathbf{1 2}$ $(100 \%)$ as opposed to the natural prenyl donor $\mathbf{2}$ (DMAPP, 58.9 $\pm 0.9 \%$ ). Assuming the same binding mode for sulfabenzamide in Fig. $6 \mathrm{~b}, \mathrm{C} 1^{\prime}$ in $\mathbf{1 2}$ could have been closer to the site of alkylation compared with $\mathrm{C}^{\prime}$ in $\mathbf{2}$. The two additional methylenes of $\mathbf{1 2}$ would be constrained out of planarity with the rest of the alkyl tail by the $s p^{3}$-hybridized carbons to which they are bonded, introducing additional steric interactions with sulfabenzamide. These new interactions likely caused the cyclopentane ring to tilt away from the acceptor compared with 2 (colored yellow in Fig. 6b), forcing $\mathrm{C} 1^{\prime}$ closer to the site of alkylation due to the planarity of the rest of the molecule.

As for the aromatic moieties, there appears to be a complex interplay between the steric and electronic characteristics of each within the binding pocket. For example, $\mathbf{5 8}$ showed the greatest conversion among all benzylic alkyl-PPs with sulfabenzamide ( $45 \pm 2 \%$ ), far surpassing its non-cyclized homolog $56(15 \pm 5 \%)$, while 46 showed the next highest conversion $(26 \pm 3 \%)$. The conformational constraint of the cyclized methylenedioxy group of $\mathbf{5 8}$ compared with the two methoxy groups of $\mathbf{5 6}$ would explain this first difference with a purely steric argument. However, the intermediate conversion of $\mathbf{4 6}$ was likely due to its capacity for lower steric hindrance than $\mathbf{5 6}$ or $\mathbf{5 8}$ balanced by a carbocation less stabilized through induction with a methyl group vs. resonance with a $p$-methoxy group. As for the non-benzylic heterocycles, turnover was observed for sulfabenzamide with 61 (13 \pm $2 \%), 62(19 \pm 2 \%)$, and $\mathbf{6 6}(9 \pm 3 \%)$. Again, steric and

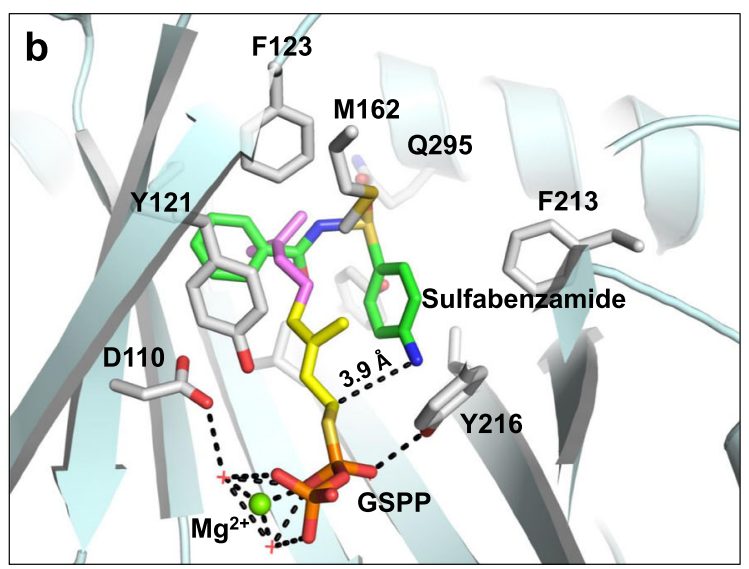

within hydrogen bonding distance ( $3.9 \AA$ ) of $\mathrm{C}^{\prime}{ }^{\prime}$ of GSPP. The $\mathrm{C}^{\prime}-\mathrm{C} 5^{\prime}$ of GSPP are colored yellow, while the $\mathrm{C}^{\prime}-\mathrm{C} 10^{\prime}$ are colored magenta

electronic factors seem to be working in complex ways to determine substrate specificity; $\mathbf{6 2}$ had the highest turnover likely because it combines a smaller ring size ( 5 vs. 6 atoms) with the higher hydrophobic character and increased resonance stabilization of the carbocation by sulfur vs. oxygen. The 5-membered ring of $\mathbf{6 1}$, however, seemed to balance its smaller size with its relative hydrophilicity and decreased carbocation stabilization, giving the second highest conversion over the larger 66. Meanwhile, the higher hydrophobicity of the sulfur in $\mathbf{6 6}$ compared with the oxygen in $\mathbf{6 5}$ was enough for the former to react at all with sulfabezamide. There were also interesting differences in the transfer of functionalized moieties onto sulfabenzamide, which only accepted five dienes $(\mathbf{6}, \mathbf{8}, \mathbf{1 6}-\mathbf{1 8})$ and a single terminal alkene (22). The accepted moieties were relatively short in length $(\sim 6$ unbranched atoms), which aligned with the general trend observed for alkyl groups transferred to sulfabenzamide. However, the inability of $\mathrm{NphB}$ to transfer alkyne substituents onto sulfabenzamide, even those resembling 2 in length $(\sim 6$ unbranched atoms), could be related to the steric clashes caused by the rotation of the linear alkynes around $\mathrm{C}-\mathrm{C} \sigma$ bonds. The same could be true for the linear azide groups, although the fully charged nitrogens may also be excluded from the overall hydrophobic NphB binding pocket. Overall, these trends illustrate that even slight modifications to donor structure can have a considerable effect on the enzyme's ability to catalyze a reaction of interest.

Understanding how these structural variations in the donor affect activity with a desired acceptor will be crucial to further develop NphB as a biocatalyst. Thus far, the enzyme has been utilized in biocatalytic systems almost exclusively for its ability to geranylate diverse aromatic acceptors (Qian et al. 2019; Valliere et al. 2019; Zirpel et al. 2017). However, the donor promiscuity established in this work opens up the possibility of utilizing $\mathrm{NphB}$ for the late-stage modification of aromatic compounds. Furthermore, using the known crystal structure of 
NphB (Kuzuyama et al. 2005), one could anticipate how engineering specific residues within the active site alters the donor specificity with an acceptor of interest, thereby introducing activity with a preferred donor. However, such applications are not limited to NphB; PTs at large are known for their promiscuity toward acceptors (Araya-Cloutier et al. 2017; Awakawa and Abe 2019; Elshahawi et al. 2017; Rudolf and Poulter 2013; Schuller et al. 2012; Wunsch et al. 2015). Therefore, the underlying concepts of acceptordependent donor specificity established for NphB most likely apply to the enzyme class as a whole.

In summary, the present study established donor specificity profiles of $\mathrm{NphB}$ with the putative acceptor 1,6-DHN and the newly identified acceptor sulfabenzamide using a synthetic library of diverse alkyl-PPs (Fig. 7). The two profiles revealed not only the general donor promiscuity of $\mathrm{NphB}$ but also the dependence of this promiscuity on the identity of the acceptor substrate. Specifically, the donor profiles of 1,6-DHN and sulfabenzamide reflect the size difference between the two acceptors, which could imply similar behavior for other prenyltransferases with known acceptor promiscuity.
Additionally, NMR characterization of representative sulfabenzamide derivatives generated in this work revealed the first reported instance of NphB-catalyzed $N$-alkylation. Taken together, the findings of the present study complement the known utility of $\mathrm{NphB}$ as a biocatalyst while simultaneously establishing its capabilities beyond geranyl transfer reactions.

Acknowledgments We gratefully acknowledge the University of Oklahoma Department of Chemistry and Biochemistry NMR and Mass Spectrometry facility for analytical support. We thank undergraduate students Johanna M. Masterson, Rachel H. Tran, and Abigail F. Lange for their participation in the synthesis of alkyl-PP analogs and J.S. Thorson for graciously providing the $\mathrm{NphB}$ expression strain.

Author contributions SS conceived and designed the research. BJ, ES, $\mathrm{DD}, \mathrm{TB}, \mathrm{CB}, \mathrm{AB}, \mathrm{EG}, \mathrm{SN}$, and SS conducted experiments. BJ, ES, DD, $\mathrm{AB}, \mathrm{SN}$, and SS analyzed the data. BJ, ES, DD, and SS wrote the manuscript. All authors read and approved the manuscript.

Funding information This work is supported in part by startup funds from the University of Oklahoma Department of Chemistry and Biochemistry (to S.S.) and an Institutional Development Award (IDeA) from the National Institute of General Medical Sciences of the National Institutes of Health under grant number P20GM103640.

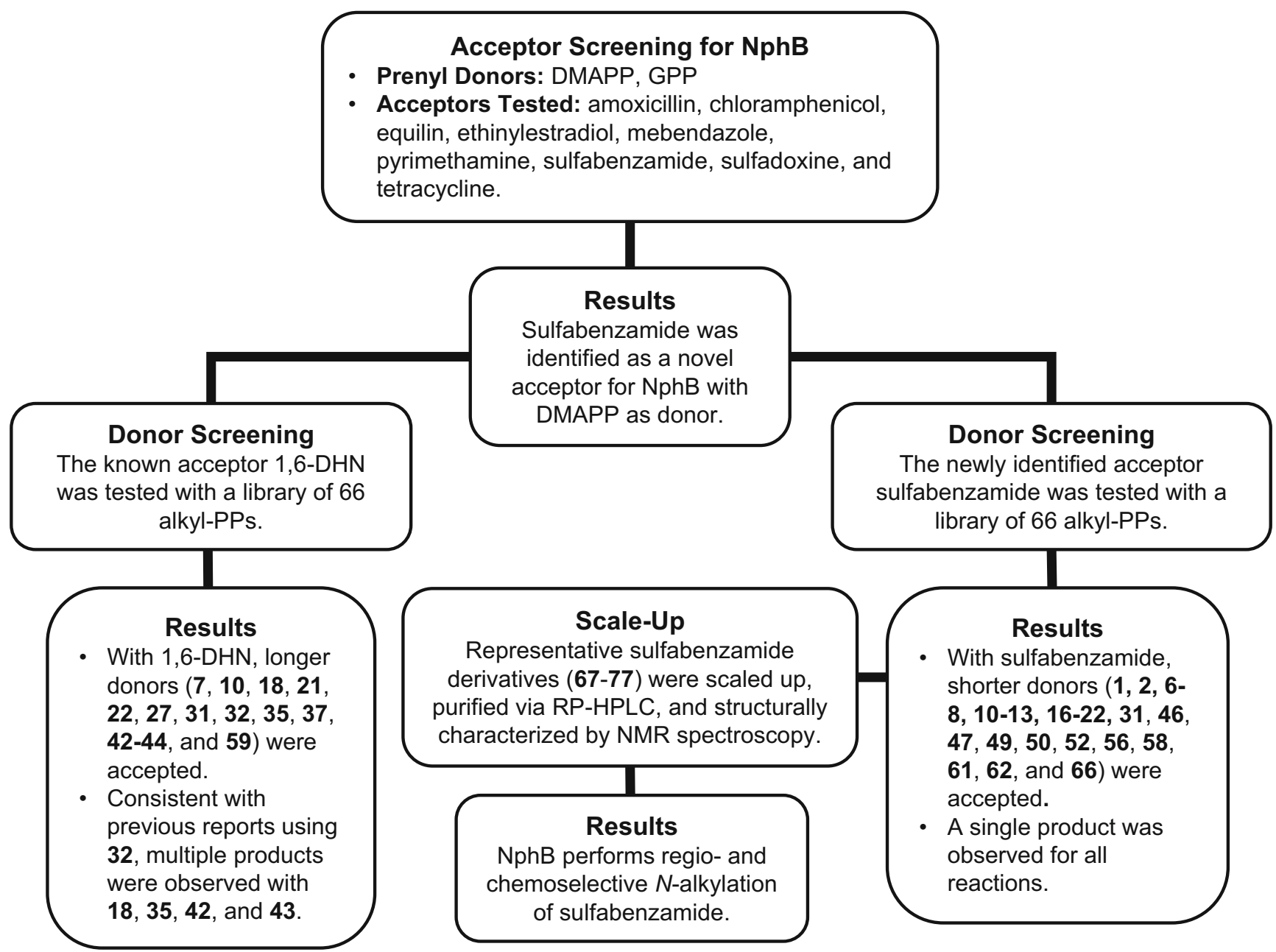

Fig. 7 Flow chart summarizing the logical progression of the methods used in this study and the major results of each step 


\section{Compliance with ethical standards}

Competing interests The authors declare that they have no conflict of interest.

Ethical statements This article does not contain any studies with human participants or animals performed by any of the authors.

Open Access This article is licensed under a Creative Commons Attribution 4.0 International License, which permits use, sharing, adaptation, distribution and reproduction in any medium or format, as long as you give appropriate credit to the original author(s) and the source, provide a link to the Creative Commons licence, and indicate if changes were made. The images or other third party material in this article are included in the article's Creative Commons licence, unless indicated otherwise in a credit line to the material. If material is not included in the article's Creative Commons licence and your intended use is not permitted by statutory regulation or exceeds the permitted use, you will need to obtain permission directly from the copyright holder. To view a copy of this licence, visit http://creativecommons.org/licenses/by/4.0/.

\section{References}

Araya-Cloutier C, Martens B, Schaftenaar G, Leipoldt F, Gruppen H, Vincken JP (2017) Structural basis for non-genuine phenolic acceptor substrate specificity of Streptomyces roseochromogenes prenyltransferase CloQ from the ABBA/PT-barrel superfamily. PLoS One 12(3):e0174665. https://doi.org/10.1371/journal.pone. 0174665

Awakawa T, Abe I (2019) Molecular basis for the plasticity of aromatic prenyltransferases in hapalindole biosynthesis. Beilstein J Org Chem 15:1545-1551. https://doi.org/10.3762/bjoc.15.157

Bandari C, Scull EM, Masterson JM, Tran RHQ, Foster SB, Nicholas KM, Singh S (2017) Determination of alkyl-donor promiscuity of tyrosine-O-Prenyltransferase SirD from Leptosphaeria maculans. ChemBioChem 18(23):2323-2327. https://doi.org/10.1002/cbic. 201700469

Bandari C, Scull EM, Bavineni T, Nimmo SL, Gardner ED, Bensen RC, Burgett AW, Singh S (2019) FgaPT2, a biocatalytic tool for alkyldiversification of indole natural products. MedChemComm 10(8): 1465-1475. https://doi.org/10.1039/c9md00177h

Bonitz T, Zubeil F, Grond S, Heide L (2013) Unusual N-prenylation in diazepinomicin biosynthesis: the farnesylation of a benzodiazepine substrate is catalyzed by a new member of the ABBA prenyltransferase superfamily. PLoS One 8(12):e85707. https://doi. org/10.1371/journal.pone.0085707

Bouchez LC, Rusch M, Larraufie M-H (2016) Diels-Alder cycloaddition in medicinal chemistry. Curr Org Chem 20(22):2358-2378. https:// doi.org/10.2174/1385272820666160216000558

Dalponte L, Parajuli A, Younger E, Mattila A, Jokela J, Wahlsten M, Leikoski N, Sivonen K, Jarmusch SA, Houssen WE, Fewer DP (2018) $\mathrm{N}$-Prenylation of tryptophan by an aromatic prenyltransferase from the cyanobactin biosynthetic pathway. Biochemistry 57:6860-6867. https://doi.org/10.1021/acs.biochem. $8 \mathrm{~b} 00879$

Elshahawi SI, Cao H, Shaaban KA, Ponomareva LV, Subramanian T, Farman ML, Spielmann HP, Phillips GN, Thorson JS, Singh S (2017) Structure and specificity of a permissive bacterial $C$ prenyltransferase. Nat Chem Biol 13(4):366-368. https://doi.org/ 10.1038/nchembio. 2285

Fan A, Winkelblech J, Li S-M (2015a) Impacts and perspectives of prenyltransferases of the DMATS superfamily for use in biotechnology. Appl Microbiol Biotechnol 99(18):7399-7415. https://doi.org/10.1007/s00253-015-6813-9

Fan A, Zocher G, Stec E, Stehle T, Li S-M (2015b) Site-directed mutagenesis switching a dimethylallyl tryptophan synthase to a specific tyrosine C3-prenylating enzyme. J Biol Chem 290(3):1364-1373. https://doi.org/10.1074/jbc.M114.623413

Giessen TW, Marahiel MA (2015) Rational and combinatorial tailoring of bioactive cyclic dipeptides. Front Microbiol 6:785. https://doi.org/ 10.3389/fmicb.2015.00785

Gregoritza M, Brandl FP (2015) The Diels-Alder reaction: a powerful tool for the design of drug delivery systems and biomaterials. Eur J Pharm Biopharm 97(Pt B):438-453. https://doi.org/10.1016/j.ejpb. 2015.06.007

Haagen Y, Unsöld I, Westrich L, Gust B, Richard SB, Noel JP, Heide L (2007) A soluble, magnesium-independent prenyltransferase catalyzes reverse and regular $C$-prenylations and $O$-prenylations of aromatic substrates. FEBS Lett 16:2889-2893

Hong J (2014) Natural product synthesis at the interface of chemistry and biology. Chemistry 20(33):10204-10212. https://doi.org/10.1002/ chem. 201402804

Kumano T, Richard SB, Noel JP, Nishiyama M, Kuzuyama T (2008) Chemoenzymatic syntheses of prenylated aromatic small molecules using Streptomyces prenyltransferases with relaxed substrate specificities. Bioorg Med Chem 16(17):8117-8126. https://doi.org/10. 1016/j.bmc.2008.07.052

Kuzuyama T, Noel JP, Richard SB (2005) Structural basis for the promiscuous biosynthetic prenylation of aromatic natural products. Nature 435(7044):983-987. https://doi.org/10.1038/nature03668

Lesburg CA, Caruthers JM, Paschall CM, Christianson DW (1998) Managing and manipulating carbocations in biology: terpenoid cyclase structure and mechanism. Curr Opin Struct Biol 8:695-703. https://doi.org/10.1016/s0959-440x(98)80088-2

Liebhold M, Li S-M (2013) Regiospecific benzylation of tryptophan derivatives catalyzed by a fungal dimethylallyl transferase. Org Lett 15(22):5834-5837. https://doi.org/10.1021/ol4029012

Liebhold M, Xie X, Li S-M (2012) Expansion of enzymatic FriedelCrafts alkylation on indoles: acceptance of unnatural $\beta$ unsaturated allyl diphospates by dimethylallyl-tryptophan synthases. Org Lett 14(18):4882-4885. https://doi.org/10.1021/ ol302207r

Liebhold M, Xie X, Li S-M (2013) Breaking cyclic dipeptide prenyltransferase regioselectivity by unnatural alkyl donors. Org Lett 15(12):3062-3065. https://doi.org/10.1021/o1401247s

Lu L, Wu ZY, Li X, Han F (2019) State-of-the-art: functional fluorescent probes for bioimaging and pharmacological research. Acta Pharmacol Sin 40(6):717-723. https://doi.org/10.1038/s41401018-0190-8

Luk LYP, Tanner ME (2009) Mechanism of dimethylallyltryptophan synthase: evidence for a dimethylallyl cation intermediate in an aromatic prenyltransferase reaction. J Am Chem Soc 131:13932-13933. https://doi.org/10.1021/cb400691z

Mahmoodi N, Tanner ME (2013) Potential rearrangements in the reaction catalyzed by the indole prenyltransferase FtmPT1. ChemBioChem 14(15):2029-2037. https://doi.org/10.1002/cbic.201300385

Meghani NM, Amin HH, Lee BJ (2017) Mechanistic applications of click chemistry for pharmaceutical drug discovery and drug delivery. Drug Discov Today 22(11):1604-1619. https://doi.org/10.1016/j. drudis.2017.07.007

Metzger U, Keller S, Stevenson CE, Heide L, Lawson DM (2010) Structure and mechanism of the magnesium-independent aromatic prenyltransferase CloQ from the clorobiocin biosynthetic pathway. J Mol Biol 404(4):611-626. https://doi.org/10.1016/j.jmb.2010.09. 067

Murray LAM, McKinnie SMK, Pepper HP, Erni R, Miles ZD, Cruickshank MC, Lopez-Perez B, Moore BS, George JH (2018) Total synthesis establishes the biosynthetic pathway to the 
naphterpin and marinone natural products. Angew Chem Int Ed Engl 57(34):11009-11014. https://doi.org/10.1002/anie.201804351

Pockrandt D, Ludwig L, Fan A, Konig GM, Li S-M (2012) New insights into the biosynthesis of prenylated xanthones: Xptb from Aspergillus nidulans catalyses an $O$-prenylation of xanthones. ChemBioChem 13(18):2764-2771. https://doi.org/10.1002/cbic. 201200545

Qian Q, Schultz AW, Moore BS, Tanner ME (2012) Mechanistic studies on CymD: a tryptophan reverse $N$-prenyltransferase. Biochemistry 51(39):7733-7739. https://doi.org/10.1021/bi3009054

Qian S, Clomburg JM, Gonzalez R (2019) Engineering Escherichia coli as a platform for the in vivo synthesis of prenylated aromatics. Biotechnol Bioeng 116(5):1116-1127. https://doi.org/10.1002/bit. 26932

Rudolf JD, Poulter CD (2013) Tyrosine $O$-prenyltransferase SirD catalyzes $S$-, $C$-, and $N$-prenylations on tyrosine and tryptophan derivatives. ACS Chem Biol 8(12):2707-2714. https://doi.org/10.1021/ cb400691z

Rudolf JD, Wang H, Poulter CD (2013) Multisite prenylation of 4substituted tryptophans by dimethylallyltryptophan synthase. J Am Chem Soc 135(5):1895-1902. https://doi.org/10.1021/ja310734n

Saleh O, Haagen Y, Seeger K, Heide L (2009) Prenyl transfer to aromatic substrates in the biosynthesis of aminocoumarins, meroterpenoids and phenazines: the ABBA prenyltransferase family. Phytochemistry 70(15-16):1728-1738. https://doi.org/10.1016/j. phytochem.2009.05.009

Schuller JM, Zocher G, Liebhold M, Xie X, Stahl M, Li S-M, Stehle T (2012) Structure and catalytic mechanism of a cyclic dipeptide prenyltransferase with broad substrate promiscuity. J Mol Biol 422(1):87-99. https://doi.org/10.1016/j.jmb.2012.05.033

Shindo K, Tachibana A, Tanaka A, Toba S, Yuki E, Ozaki T, Kumano T, Nishiyama M, Misawa N, Kuzuyama T (2011) Production of novel antioxidative prenyl naphthalen-ols by combinational bioconversion with dioxygenase PhnA1A2A3A4 and prenyltransferase NphB or SCO7190. Biosci Biotechnol Biochem 75(3):505-510. https://doi. org/10.1271/bbb.100731

Tanner ME (2015) Mechanistic studies on the indole prenyltransferases. Nat Prod Rep 32(1):88-101. https://doi.org/10.1039/c4np00099d

Taylor AP, Robinson RP, Fobian YM, Blakemore DC, Jones LH, Fadeyi O (2016) Modern advances in heterocyclic chemistry in drug discovery. Org Biomol Chem 14(28):6611-6637. https://doi.org/10. 1039/c6ob00936k

Tello M, Kuzuyama T, Heide L, Noel JP, Richard SB (2008) The ABBA family of aromatic prenyltransferases: broadening natural product diversity. Cell Mol Life Sci 65(10):1459-1463. https://doi.org/10. 1007/s00018-008-7579-3
Valliere MA, Korman TP, Woodall NB, Khitrov GA, Taylor RE, Baker D, Bowie JU (2019) A cell-free platform for the prenylation of natural products and application to cannabinoid production. Nat Commun 10(1):565. https://doi.org/10.1038/s41467-019-08448-y

Winkelblech J, Fan A, Li S-M (2015a) Prenyltransferases as key enzymes in primary and secondary metabolism. Appl Microbiol Biotechnol 99(18):7379-7397. https://doi.org/10.1007/s00253-015-6811-y

Winkelblech J, Liebhold M, Gunera J, Xie X, Kolb P, Li S-M (2015b) Tryptophan C5- , C6- and C7-prenylating enzymes displaying a preference for $C 6$ of the indole ring in the presence of unnatural dimethylallyl diphosphate analogues. Adv Synth Catal 357(5): 975-986. https://doi.org/10.1002/adsc.201400958

Wunsch C, Zou HX, Linne U, Li S-M (2015) C7-prenylation of tryptophanyl and O-prenylation of tyrosyl residues in dipeptides by an Aspergillus terreus prenyltransferase. Appl Microbiol Biotechnol 99(4):1719-1730. https://doi.org/10.1007/s00253-0145999-6

Xiao Y, Machacek M, Lee K, Kuzuyama T, Liu P (2009) Prenyltransferase substrate binding pocket flexibility and its application in isoprenoid profiling. Mol BioSyst 5(9):913-917. https:// doi.org/10.1039/b902370d

Yang Y, Miao Y, Wang B, Cui G, Merz KM Jr (2012) Catalytic mechanism of aromatic prenylation by NphB. Biochemistry 51(12):26062618. https://doi.org/10.1021/bi201800m

Yin WB, Ruan HL, Westrich L, Grundmann A, Li S-M (2007) CdpNPT, an $\mathrm{N}$-prenyltransferase from Aspergillus fumigatus: overproduction, purification and biochemical characterisation. ChemBioChem 8(10):1154-1161. https://doi.org/10.1002/cbic.200700079

Yu H, Liebhold M, Xie X, Li S-M (2015) Tyrosine $O$-prenyltransferases TyrPT and SirD displaying similar behavior toward unnatural alkyl or benzyl diphosphate as their natural prenyl donor dimethylallyl diphosphate. Appl Microbiol Biotechnol 99(17):7115-7124. https://doi.org/10.1007/s00253-015-6452-1

Zirpel B, Degenhardt F, Martin C, Kayser O, Stehle F (2017) Engineering yeasts as platform organisms for cannabinoid biosynthesis. J Biotechnol 259:204-212. https://doi.org/10.1016/j.jbiotec.2017.07. 008

Zou HX, Xie X, Zheng XD, Li S-M (2011) The tyrosine $O$ prenyltransferase $\operatorname{SirD}$ catalyzes $O-, N-$ and $C$-prenylations. Appl Microbiol Biotechnol 89(5):1443-1451. https://doi.org/10.1007/ s00253-010-2956-X

Publisher's note Springer Nature remains neutral with regard to jurisdictional claims in published maps and institutional affiliations. 